\title{
Fish's Muscles Distortion and Pectoral Fins Propulsion of Lift-Based Mode
}

\author{
S. B. Yang*, X. Y. Han, J. Qiu \\ Institute of Mechatronical Engineering, National University of Defense Technology, Changsha 41007., \\ China \\ Email: yangshaobo2004@yahoo.com.cn
}

\begin{abstract}
As a sort of MPF(median and/or paired fin propulsion), pectoral fins propulsion makes fish easier to maneuver than other propulsion, according to the well-established classification scheme proposed by Webb in 1984. Pectoral fins propulsion is classified into oscillatory propulsion, undulatory propulsion and compound propulsion. Pectoral fins oscillatory propulsion, is further ascribable to two modes: drag-based mode and lift-based mode. And fish exhibits strong cruise ability by using lift-based mode. Therefore to robot fish design using pectoral fins lift-based mode will bring a new revolution to resources exploration in blue sea. On the basis of the wave plate theory, a kinematic model of fish s pectoral fins lift-based mode is established associated with the behaviors of cownose ray (Rhinoptera bonasus) in the present work. In view of the power of fish's locomotion from muscle distortion, it would be helpful benefit to reveal the mechanism of fish's locomotion variation dependent on muscles distortion. So this study puts forward the pattern of muscles distortion of pectoral fins according to the character of skeletons and muscles of cownose ray in morphology and simulates the kinematics of lift-based mode using nonlinear analysis software. In the symmetrical fluid field, the model is simulated left-right symmetrically or asymmetrically. The results qualitatively show how muscles distortion determines the performance of fish locomotion. Finally the efficient muscles distortion associated with the preliminary dynamics is induced.
\end{abstract}

\section{REFERENCES}

1. Webb P W. Form and function in fish swimming. Sci Amer. 1984; 251: 58-68

2. Heine C. Mechanics of flapping fin locomotion in the cownose ray, Rhinoptera bonasus (Elasmobranchii: Myliobatidae). Duke University. 1992

3. Compagno L J V. Endoskeleton. In: Hamlett Wc, ed. Sharks, Skate, and Rays: the Biology of Elasmobranch Fishes. Baltimore: John Hopkins University Press. 1999, pp.69-92

4. Schaefer J T, Summers A P. Batoid wing skeletal structure: novel morphologies mechanical implications, and phylogentic patterns. Journal of Morphology. 2005; 264: 298-313

5. Liem K F, Summers A P. Muscular system: gross anatomy and functional morphology of muscles. In: Hamlett W C, ed. Sharks, skates and rays: the biology of elasmobranches fishes. Baltimore: John Hopkins University Press. 1999; 93-114

6. Clark R P, Smits A J. Thrust production and wake structure of a batoid-inspired oscillating fin. $J$ Fluid Mech, 2006; 562: 415-429

7. Yang S B, Han X Y, Qiu J. Kinematic simulation of pectoral fin lift-based locomotion in cownose ray (Rhinoptera bonasus). Reviewing

8. Rosenberger L J. Pectoral fin locomotion in batoid fishes: undulation versus oscillation. The Journal of Experimental Biology, 2001; 204: 379-394 